\title{
Cytarabine/Mitoxantrone Regimen
}

National Cancer Institute

\section{Source}

National Cancer Institute. Cytarabine/Mitoxantrone Regimen. NCI Thesaurus. Code C9623.

A chemotherapy regimen consisting of cytarabine and mitoxantrone that may be used in the treatment of acute myeloid leukemia (AML). 